\title{
To assess the Influence of Selected Community Based Factors on Girls' Participation Rate in Public Day Secondary Schools in Naivasha Sub-County, Kenya.
}

\author{
Janet Waithira Gatere, Prof. J. Kanjogu Kiumi, Dr. Margaret Ngugi
}

Department of Curriculum and Education Management, Laikipia University, Kenya. Correspondence:

\begin{abstract}
The purpose of this study was to assess the influence of selected community based factors on girls' participation rate in public day secondary schools in Naivasha Sub-County, Kenya. Ex-post facto research design was used in the study. A total of 130 respondents (constituting 26 principals and 104 teachers) from 26 schools were randomly sampled for the study. All the targeted respondents participated in the study giving a response rate of $100 \%$. Simple random sampling technique was used to sample the respondents for the study. Data was collected through a self-administered questionnaire where two sets of questionnaires were developed for data collection; one for principals and the other for class teachers. Descriptive statistics such as means, percentages and frequencies were used to analyze the data while inferential statistics such as simple regression analysis was used to determine the predictive power of community factors on girls' participation in school. The study found that three community-level risk factors that had the most negative effect on girls' participation in public day secondary schools in the study area including: negative peer influence in the community, high incidences of teenage pregnancies and poverty in the community. Drawing from the computed $\mathrm{R}^{2}$ value $\left(\mathrm{R}^{2}=.406\right)$, the study revealed that the selected community factors were lowering the rate of girls participation in public day secondary schools by almost $41 \%$. The study concluded that prevalence of the three community level factors such as: high incidence of teenage pregnancies and poverty had great influence on girls' participation and progression in public day secondary schools in the study area. It was recommended that school, family and community partnerships would be appropriate in minimizing the effect of community level factor on girls' participation in schools.
\end{abstract}

Key Words: Girls' Participation, Community Based Factors, Participation Rate

\section{Introduction}

Formal education plays a key role in the overall development process in a nation. This view is grounded in the fact that education does not only equip citizens with knowledge and skills but is also a critical tool for imparting values deemed necessary for the growth and development of a nation. Psacharopoulos (1987) has further observed that investment in human capital through formal education is the most effective way of stimulating positive development in a country. It is for this reason that the government of Kenya has continued to invest heavily in education due to the conviction that education and training are important ingredients for the creation of manpower requirements in all aspects of national development.

One of the critical determinants of successful growth and development process in a nation is access to quality learning in the lower levels of education system. The lower levels of education in Kenya comprise three sub- systems namely, pre-primary, primary and secondary cycles (Republic of Kenya, 2013). The latter prepares learners for further education and training in post-secondary institutions. Additionally, secondary education sub-system in Kenya aims at promoting the growth of an individual towards maturity and selffulfillment so as to make the individual to be a useful and well-adjusted member of the society. 
In spite of the immense role that education plays in a nation, it is disheartening to mention that there are gender disparities in favor of boys in regard to access and participation at the basic level of education. The disparity in gender participation in secondary school is in regard to enrolment, retention and completion of secondary school cycle in education where the girls are disadvantaged. Data from WMS III (1997) indicates that men have a higher enrolment, retention and completion rate in the secondary school cycle of education compared to women irrespective of poverty levels and region. UNDP (2002) further observed that globally, total enrolment of boys in both primary and secondary schools was 55\% while that of girls stood at $45 \%$ in 2001. A similar scenario is prevalent in Kenya. For instance, as was observed by FAWE (2005), enrolment of girls in the country's basic education sector was not at parity with that of boys owing to the tendency by girls to drop out of the education system before reaching the final grade. This enrolment disparity was similarly noted by the Ministry of Education (2005) which observed that inspite of increased public investment in basic education, girls' level of enrolment and completion rates were a challenge, particularly in the arid parts of the country. The noted gap in girls' participation rate in Kenya's basic education sector is aptly demonstrated in table1 with regard to the secondary education cycle between 2009 and 2014.

Table 1 : Enrolment in Secondary (Nationally) by Gender 2009 - 2014 in Thousands ('000) and Gender Parity Index

\begin{tabular}{|l|c|c|c|c|}
\hline Year & \multicolumn{2}{|c|}{ Gender } & Total & Parity index (Girls/Boys) \\
\hline & Boys & Girls & & 0.87 \\
\hline 2009 & 787.9 & 684.7 & 1472.6 & 0.87 \\
\hline 2010 & 885.5 & 767.8 & 1653.4 & 0.86 \\
\hline 2011 & 948.7 & 819.0 & 1767.7 & 0.88 \\
\hline 2012 & 1019.0 & 895.8 & 1914.8 & 0.87 \\
\hline 2013 & 1127.7 & 976.6 & 2104.3 & 0.92 \\
\hline
\end{tabular}

Source: Ministry of Education, Science and Technology, 2014.

A look at the data presented in table 1 reveals that there was gender enrolment disparity in favour of boys at the secondary education cycle for the period running between 2009-2014. There was a similar scenario in Naivasha Sub-county where the study was carried out as shown in table 2.

Table 2 : Student Enrolment in Naivasha Sub - County by Gender (2007 - 2011)

\begin{tabular}{|l|c|c|c|}
\hline Year & \multicolumn{2}{|c|}{ Gender } & TOTAL \\
\hline 2010 & Male & Female & \\
\hline 2011 & $3177(53.9)$ & $2764(46.1)$ & 5891 \\
\hline 2012 & $3370(53.6)$ & $2923(46.4)$ & 6293 \\
\hline 2013 & $3376(51.9)$ & $3122(48.1)$ & 6498 \\
\hline 2014 & $4449(53.7)$ & $3840(46.3)$ & 8289 \\
\hline 2015 & $5292(50.1)$ & $5269(49.9)$ & 10,561 \\
\hline 2016 & $6032(50.6)$ & $5883(49.4)$ & 11,915 \\
\hline Total & $7007(55.8)$ & $5543(44.2)$ & 12,550 \\
\hline
\end{tabular}

(Figures in parenthesis represent percentages)

Source: Naivasha Sub-county Secondary School Enrolment Data (2016).

An examination of the summarized data in table 2 demonstrates that there was gender enrolment disparity in favour of boys in Naivasha Sub-county between 2009 and 2016. This implies that, in spite of the introduction of free secondary education in Kenya in 2008, girls' enrolment in secondary schools in the subcounty is yet to be at par with that of boys. Indeed, the Kenya Certificate of Secondary Education (KCSE) exit examination candidature, as shown in table 3 clearly shows that boys outnumbered girls for the six years captured in the table. 
Table 3 : Number of Students Enrolled for KCSE Examination in Naivasha Sub - County by Gender Between the Year 2011 and 2016

\begin{tabular}{|l|c|c|c|}
\hline Year & No. of Male & No. of Females & Total \\
\hline 2011 & $1035(51)$ & $995(49)$ & 2030 \\
\hline 2012 & $1151(50.2)$ & $1143(49.8)$ & 2294 \\
\hline 2013 & $1291(52.9)$ & $1150(47.1)$ & 2441 \\
\hline 2014 & $1522(50.2)$ & $1508(49.8)$ & 3030 \\
\hline 2015 & $1785(51.8)$ & $1659(48.2)$ & 3444 \\
\hline 2016 & $1880(50.9)$ & $1806(49.1)$ & 3686 \\
\hline Total & $\mathbf{8 6 6 4 ( 5 1 . 2 )}$ & $\mathbf{8 2 6 1}(\mathbf{4 8 . 8})$ & $\mathbf{1 6 , 9 2 5}$ \\
\hline
\end{tabular}

Source: Naivasha Sub-county student enrolment data (2016)

There is a need to point out that aggregate candidature in exit examination is a reliable indicator of total student enrolment and successful progression of enrollees up to the terminal grade or class for that matter. In this regard, it can be argued that girl's enrolment in secondary schools in Naivasha Sub-county has been consistently lower than that of boys. Alternatively, there are chances that girls could be dropping out of secondary schools in the sub-county before reaching the final grade.

Admittedly, women play multiple roles in production and reproduction at the household and societal level (Todaro, 1985). In this regard, a country is highly likely to achieve more returns by educating its women. For instance, basic education for women does not only lower fertility rates but also increases agricultural output since women are the main agricultural subsistence producers, more so in the developing world (World Bank, 1989). Moreover, Article 53 (1) of Kenya's constitution aptly states that every child irrespective of gender has a right to free and compulsory basic education (Republic of Kenya, 2013). This constitutional provision is further articulated in the Basic Education Act whose article 4 stipulates that provision of basic education in Kenya shall be guided by the principle of the right of every child to free and compulsory basic education and elimination of gender discrimination at all levels of basic education (Republic of Kenya, 2013).

Drawing from the foregoing statutory provisions, it can rightly be argued that low girls' participation in secondary education in Kenya limits their full enjoyment of one of the basic human rights. Moreover, differential access (in favour of boys) to secondary education denies the country the expected pay-offs from educated women. For instance, educated women are not only more likely to have fewer children, thereby lowering the socio-economic burdens associated with large families but have also higher chances of availing requisite provisions for their children including quality healthcare and education (Chiuri \& Kiumi, 2005, Yieke, 2015).

The Government of Kenya has initiated strategies to enhance gender parity in access to secondary education. These strategies among others include, positive discrimination in favour of girls during admission to form one, creation of girls rescue centers in arid regions, provision of sanitary towels to girls in secondary schools in low income regions, campaigns against Female Genital Mutilation (FGM) and implementation of the "Return to School Policy" for young mothers (Republic of Kenya, 2006, Republic of Kenya, 2005). In spite of the foregoing cited initiatives, girls are yet to catch up with their male counterparts in accessing secondary education, particularly in disadvantaged regions of the country. Some of the factors severally cited in documented literature (research based and otherwise) include backward cultural practices in the community (e.g., FGM, early marriages, inadequate positive role models in the community and tendency by some communities to disvalue girl child education (Republic of Kenya, 2006; Bruns \& Mingat, 2003).

Other factors that have been linked to low girls' participation in secondary education are those rooted in child's home environment. For example girls hailing from poor households tend to experience the duo challenges of inadequate supply of personal effect and being forced by parents to argument family resources through engagement in income generating activities like hawking, cleaning utensils in food kiosks, selling fruits and vegetables in market places and babysitting, (Kiome, 2015; Chiuri \& Kiumi, 2005, Ministry of Education, 2007). Girls affected by these negative factors tend to withdraw from school prematurely. 
Furthermore, poor families are less likely to provide for their children including argumentation of education with resources at home that can spark and sustain interest in learning in the absence of the teacher (Kiumi, Kibe, \& Ng'ang'a, 2013). This scenario has the potential to make a child lose interest in education, a factor that may compel the child to dropout from school. In most cases, girls tend to be more affected than boys due to the tendency by economically poor parents to attach a low premium on girl child education (Sifuna, 2006).

Apart from community and home based factors, existing literature consistently shows that the school environment has a significant share in regard to the global factors attributed to the relatively higher enrolment gap of girls in secondary schools compared to boys. Some of the documented factors include, lack of girl friendly facilities, specifically latrines that can provide some privacy, lack or inadequate provision of sanitary towels and bullying by their male colleagues in co-educational schools (UNESCO, 2003; Girl Child Network, 2008). It has similarly been observed that in a school environment where teachers subscribe to the view that girls are less endowed intellectually, girls may be relegated to the periphery in regard to academic matters at the classroom and school-wide levels. Kendall (2006) has for instance reported on a study carried out by USAID in Malawi which revealed that girls in most schools were not only perceived by teachers as dull / weak, but were also assigned low status tasks such as sweeping and arranging classroom furniture. Comparatively, boys were viewed as intellectually strong which explained why they were allocated higher status tasks such as timekeeping and bell ringing. Proceeding from the foregoing expositions, girl-child education at the secondary level of education, it can be reasoned that for girls to enjoy fully their basic right to secondary education in addition to enabling them to play their rightful role in society, there is need to both document and mitigate obstacles that could be hindering their full participation at this level of education.

\subsection{Statement of the Problem}

Secondary school education in Kenya is a basic human right irrespective of a child's gender. Nonetheless, although the government of Kenya is committed to this philosophy, girl's enrolment in secondary schools is yet to be at par with that of boys. Documented literature seems to indicate that unfavorable community environment is one of the risk factors that impact negatively on girl's participation in secondary education. However, the extent to which this factor influences girls' participation rate in public day secondary schools has not been investigated. To fill the gap that exists in the literature, this study sought to assess the influence of selected community based factors on girls' participation rate in public day secondary schools in Naivasha Sub-County, Kenya.

\section{II: Literature Review}

This section presents the theories used in the study and the relevant literature on the influence of community based factors on the participation of girls in schools.

\subsection{Theoretical Framework}

Theories of Prejudice and Discrimination and Muted group theory were used in this study.

\section{Theories of Prejudice and Discrimination}

These include the Gender schema theory (Bern, 1981) which postulates that children learn how their cultures and or societies define the roles of men and women and then internalize this knowledge as a gender schema or unchallenged core belief. The gender schema is then used to organize experiences (Bern, 1993). Eventually, children will incorporate their own self-concept into their gender schema and assume some traits and behavior that they deem.

Additionally Eagly's social role theory states that the inherent physical differences between men and women led to a division of labour in society. The theory suggests that most behavioral differences we know about males and females is the result of cultural stereotypes about gender, (how males and females are supposed to act) and the resulting social roles that are taught to young people (Eagly, 1987).

\section{Muted Group Theory}


This is a critical theory because it is concerned with power and how it is used against people. The theory chooses to bifurcate the power spectrum into men and women. The theory was developed by social anthropologists Edwin Ardener and Shirley Ardener in 1975. It focuses on the ways that the communication practices of dominant groups suppress, mute, or devalue the words, ideas, and discourses of subordinate groups. According to the theory certain groups of people remain powerless compared to others. The muted group theory explains the cause of muteness by a certain group of a population especially of that of women in the society. This implies that the muted group does not access equality in education and that their views are disregarded in society.

\subsection{Influence of Community Based Factors on the Participation of girls in Secondary School Education}

These are factors in the community that impact negatively on girls' participation in school. They include cultural discrimination against girls education, pregnancy and early marriages, negative cultural practices like FGM, negative attitude towards girl education, gender stereotyped roles, discrimination and peer pressure among others.

\section{Influence of Negative Cultural Practices}

Kapakasa (1992) in her study on determinants of girls' participation and persistence in school, found that initiation ceremonies contributed significantly to school dropout as parents demonstrated willingness to pay more for initiation of their daughters than for regular schooling. Since initiation prepares young girls for marriage life, the girls choose to put into practice what they learn at the initiation ceremonies rather than continue with schooling. Kainja and Mkandawire (1989) also contended that while girls as well as boys experience multiple repetition, girls are at a disadvantage because the onset of adolescence brings competing demands in school, at home and in the community with the risk of pregnancy and early marriage.

Traditionally, initiation, circumcision and early marriage should not cause girls to drop out of school. Wanyoike (2003) states that some students who drop out of school especially girls end up in early marriages and prostitution. However, a survey carried out among Samburu community indicates that girls are forced to early marriage at a tender age of 13 years. Threats of curses befalling those who refuse to get married make it difficult for girls to resist early marriages. Some continue with schooling after marriage but when they get pregnant they have to quit school (Wanyoike, 2003). This disadvantages the girls as the boys are left to continue with school. Retrogressive ceremonies like female genital mutilation (FGM) and thereafter engagement for marriage results to low attitude towards education by girls. Initiation ceremonies were still important in some African communities because they mark the passage from childhood to adulthood. During initiation ceremonies, knowledge and value concerning procreation, morals and sexual skills, birth control and pregnancy were passed to the girls. After initiation it is considered shameful for girls to return to school unlike the boys (Omare, 2007). The study sought to establish the influence of negative cultural practices on the participation of the girls in secondary schools in Naivasha Sub-county, Kenya.

\section{Influence of Gender Stereotyped Roles}

Culturally determined ways of defining women and men and their roles in a given society shape genderspecific opportunities and constraints. Thus, the existence of discriminatory attitudes towards the schooling of girls is informed by customs and culture. Mobility restrictions arise in many societies when girls reach puberty and this makes the effect to be more on girls' retention than on entry (Lloyd and Blanc 1996). Indeed, girls' behaviour is often directly related to the many tribal and traditional taboos which dictate what and what not to do at the various stages of their development which may conflict with the demands of schooling. The different roles allocated at home to boys and girls affect girl's performance in school. The girls have less time to do supplementary studies after school compared to the boys (Wamahiu, Opondo \& Nyagah 1992).

As children grow up they socialize differently, with girls being taught one set of values and boys another. At a very young age, girls begin to understand and imbibe the culture of meekness, subservience, conformity and domesticity. They accept duties assigned in accordance with traditional gender specific advisor of labour. Son preferences and parent's perceptions and attitudes towards schooling of girls give education in 
Africa and elsewhere have long been plagued with pedagogy of difference by way of education that stresses the difference between boys and girls even men and women rather than similarities (FAWE, 2009), such pedagogy differences start at home and end in community. Davison and Kanyuka (1990) observed, cultural factors in Malawi and gender specific attitudes about the division of labour also shape the decisions about whether a child should or should not be in school.

Anderson (1988) also argued that the disadvantage of girls' education is mediated through gender-based divisions of labour and social roles. Thus, there are in most societies, gender-based divisions of labour in both the production of goods and services and in household-based production which affect access to schooling. In addition, parents in Malawi, show a strong preference for educating sons than daughter (Kainja and Mkandawire 1989, Davison and Kanyuka 1990). The study sought to establish the influence of gender discrimination in terms of chores allocated to boys and girls on the participation of the girls in secondary schools in Naivasha Sub-county, Kenya.

\section{Influence Teenage Pregnancies and Early Marriages}

In majority of African culture child bearing is associated with adults. This means pregnant girls are viewed as 'adults' and have no business being in school. Therefore these pregnant girls are expelled from school (Okumu, 1995). Fatuma (2006) attributes high drop out among girls due to pre-marital pregnancies which was characterized by frequent sexual harassment.

The national policy of education in MOEST (2005) requires girls who are pregnant to enroll back to school. However this is a challenge due to cultural backgrounds and the parents may not be motivated to take the girls back to school. A recent survey on the policy of pregnant girls required to re-enroll back to school faced a lot of challenges as reported by Mutambai (2005). It was reported that the policy lacked proper monitoring evaluation mechanisms (Fatuma \& Sifuna, 2006).

According to the Daily Nation Newspaper, (10 ${ }^{\text {th }}$ August,2012,pg. 3), a girl from a remote village in Pokot, had made up her mind never to go back to school in second term of form one because she suffered trauma at the hands of the warriors in her community who treated her like an outcast due to her academic excellence. They planned to marry her off and the girl vowed never to go back to school for fear of community rejection. However, it took the combined effort of the secondary school principal and her sponsors; the Nation Media Group to convince her to go back to school. This was after she was counseled and assured of support by the principal until she completes form four and realizes her dream of becoming a doctor.

Brown (1980) indicates that some children are withdrawn by parents in rural areas to assist in household chores like taking care of younger siblings, accompanying parents to the farm, collecting firewood and water, caring for the sick relatives among others. The girl - child does most of this work but where there are no girl siblings, the boys are used to perform these tasks. This clearly shows gender discrimination in that boys assist at home only when there are no girls, which affect girls' education to an extent of dropping from school due to constant absenteeism (Wanjiru, 2007).

Pregnancy before marriage not only leads to girls' dropout of school but also brings shame to the family. In their study on factors affecting girls' participation in secondary education in six developing countries, Brock and Cammish (1991) reported that teenage pregnancy reduces the bride price, parents therefore fear allowing their daughters to stay in school for too long. Marriage is also seen as making one gain a high social status, some parents also are not willing to educate their daughters due to the change of allegiance after marriage to their husband's family. Due to this, parents turn to educating boys. In societies where marriage of girls tend to occur at a much younger age than that of the boys, where religious or customary beliefs discourage social interaction between the societies or where conventional opinions encourage women to see their future as being centered on the home and the family, the incentive for girls to attend school is lower than that of the boys. The study was set to investigate the influence of teenage pregnancy and early marriages on the participation of girls in secondary schools in Naivasha Sub-county, Kenya.

Influence of Community's Negative Attitude towards Girls Education 
World Bank (1996) acknowledges that in developing countries including Africa, there are socio-cultural norms which permeate the school's functioning. Wanjiru (2007) states that girls are socialized to know that their brothers education is much more important than theirs and they are ready to drop-out of school for the sake of the education of their brothers. Wanyoike (2003) concurs with Wanjiru and observed that the way the family foundations are laid down, it is difficult to erase the attitudes and behavior patterns that are formed about girls and boys. He further observes that the boys and girls are received differently at birth thus attaching diverse value to them. Boys are valued to be superior to girls and hence even in education they are given a priority in some societies. The extent to which community based factors influence the participation of girls in secondary schools has not been investigated. This study was set to fill this gap with a view to coming up with findings that could offer practical solutions to the factors in the community that impart negatively on girls' participation in secondary school education in Naivasha Sub-county.

\section{III: Methodology}

This study was carried out in public secondary schools in Naivasha Sub-county of Nakuru County, Kenya. The population for the study included 28 principals and 112 class teachers in the 28 public secondary schools in Naivasha Sub-county. Ex-post facto research design was used in the study. According to Krecjie and Morgan's (1970) sampling formulation, the ideal sample size (n) in a population of 28 subjects is 26 cases. This is equivalent to $93 \%$ of the total number of subjects in the population. Thus a total of 130 respondents (constituting 26 principals and 104 teachers) from 26 schools were randomly sampled for the study. All the targeted respondents participated in the study giving a response rate of $100 \%$. Data was collected through a self-administered questionnaire where two sets of questionnaires were developed for data collection; one for principals and the other for class teachers. Five point likert scale was used in the questionnaire where the scoring was done using a tick against the statement given in scale from strongly disagree, disagree, not sure, agree and strongly agree. The collected data were edited, coded and entered into SPSS version 22 for analysis. Descriptive statistics such as means, percentages and frequencies were used to analyze the data while inferential statistics such as simple regression analysis was used to determine the predictive power of community factors on girls' participation in school.

\section{Findings of The Study}

This section presents the findings of the study on the influence of selected community based factors on girls' participation rate in public day secondary schools in Naivasha Sub-County, Kenya.

\subsection{Community Based Factors and Girls' Participation rate in Secondary Schools}

Respondents' (teachers) mean scores on perceived influence of community based factors on girls' participation in secondary schools are summarized in table 4.

Table 4 : Perceived Level of Influence of Selected Community Based Factors on Girls' Participation in Secondary Schools

\begin{tabular}{|l|c|}
\hline Factor & Mean score \\
\hline High incidence of teenage pregnancies & 3.10 \\
\hline Minimum involvement of educated females in community affairs & 3.05 \\
\hline Girls' discrimination in education matters in the community & 2.48 \\
\hline Lack of appropriate role models for girls in the community & 2.99 \\
\hline Effect of Peer pressure in the community & 3.40 \\
\hline Low regard for girl-child education in the community & 2.83 \\
\hline High incidence of Poverty in the community & 3.09 \\
\hline Negative cultural practices such as FGM & 3.16 \\
\hline Negative religious beliefs and practices & 2.39 \\
\hline Insecurity in the community influences & 2.27 \\
\hline Overall mean score & 2.88 \\
\hline
\end{tabular}

Drawing from PL1 schema presented earlier in table 4, it can be reasoned that the global perceived level of influence of the ten selected community factors on girls' rate of participation in public day secondary 
schools was low (mean $=2.88$ ). The data, however shows that negative peer influence in the community (mean $=3.40)$, had a high negative effect on girls rate of participation in secondary schools followed by negative culture practices, specifically FGM (mean=3.16), high incidence of teenage pregnancies $($ mean $=$ $3.10)$, high incidence of poverty in the community (mean $=3.09)$, and low level of involvement of educated females in community affairs (mean $=3.05$ ). Conversely, insecurity in the community had the lowest negative influence on girls participation in secondary schools in the study area (mean $=2.27)$. The other factors that had similarly low level of influence were girls discrimination in education matters in the community (mean=2.48), and negative religious beliefs and practices in the community (mean $=2.39$ ).

\subsection{Predictive Capacity of Community Factors on Girls Rate of Participation in Secondary Schools}

The purpose of the study was to find out whether the selected community factors have any influence on girls' rate of participation in public day secondary schools in the study area. To realize the purpose of the study, null hypothesis was formulated as follows:

$\mathrm{HO}_{1}$ : Community based factors have no statistically significant influence on girls' participation rate in public day secondary schools in Naivasha Sub-county, Kenya.

The hypothesis presumed that community based factors have no statistically significant influence on girls participation rate in public day secondary schools in the study area.

In order to ascertain the truth of this assumption, scores generated from the likert items in class teachers' questionnaire were subjected to simple regression analysis. The results of simple regression analysis are summarized in table 5.

Table 5 : Regression Analysis Summary between Community Factors and Girls Participation Rate in Public Day Secondary Schools

\begin{tabular}{|l|l|l|l|l|l|l|}
\hline Variable & & $\mathrm{R}$ & $\mathrm{R} 2$ & $\mathrm{df}$ & $\mathrm{F}$ & $\mathrm{p}$-value \\
\hline Dependent & $\begin{array}{l}\text { Girls' participation rate in public } \\
\text { day secondary schools }\end{array}$ & .454 & .406 & 91 & 3.117 & $.006^{*}$ \\
\hline Independent & Selected community factors & & Beta $(\beta)$ & $\mathrm{t}$ & & $.006^{*}$ \\
\hline & & & -355 & -4.028 & & \\
\hline
\end{tabular}

*Significant at .05 alpha level

Table 5 presents several statistical indices in regard to the link between community factors and girls rate of participation in public day secondary schools. From the table, it can be learnt that the F-value was statistically significant $(\mathrm{F}=3.117 ; \mathrm{df}=91 ; \mathrm{P}<.05)$. This implies that there was a statistically significant linear relationship between the selected community factors and girls' participation rate in public day secondary schools in the study area. In other words, the selected community factors had the capacity to predict girls rate of participation in public day secondary schools in the study locale. Table 16 further shows that the beta coefficient $(\beta=.355)$ was negative and statistically significant $(t=-4.028 \mathrm{p}<.05)$. This indicates that the selected community factors had a statistically significant negative influence on girls rate of participation in public day secondary schools. Drawing from the computed $\mathrm{R}^{2}$ value $\left(\mathrm{R}^{2}=.406\right)$, it can be reasoned that, the selected community factors were lowering the rate of girls participation in public day secondary schools by almost $41 \%$. On the basis of the findings presented in table 16, the formulated null hypothesis $\left(\mathrm{HO}_{1}\right)$ was rejected and conclusion made that the selected community factors and girls rate of participation in public day secondary schools in Naivasha Sub-county were not statistically independent. This implies that the selected community factors were a reliable predictor of the rate of girls' participation in public secondary schools in the sub-county. Thus, if the selected risk factors in the community are addressed the rate of girls participation in public day secondary schools in the study area is likely to improve by $41 \%$.

\subsection{Teachers' Suggestions for Mitigating Community Level Risk Factors to Girls' Participation in Public Day Secondary Schools}

Teachers were asked to give suggestions on the ways of mitigating the influence of community level risks on the participation of girls in public secondary schools in Naivasha sub-county. The suggestions given were as summarized on table 6 below. 
Table 6 : Teachers' Suggestions for Mitigating Community Level Risk Factors to Girls' Participation in Public Day Secondary Schools

\begin{tabular}{|l|c|c|}
\hline Suggestions & Frequency (f) & Percentage (\%) \\
\hline $\begin{array}{l}\text { Educate parents and guardians on the need to support the } \\
\text { education of girls }\end{array}$ & 13 & 10 \\
\hline $\begin{array}{l}\text { School managers to create child friendly environment in } \\
\text { schools }\end{array}$ & 11 & 8 \\
\hline NGO'S to sponsor schooling of needy girls & 17 & 7 \\
\hline Improve guidance and counseling services in schools. & 20 & 15 \\
\hline $\begin{array}{l}\text { Government to enforce laws to protect the right of girls to } \\
\text { education }\end{array}$ & 25 & 22 \\
\hline $\begin{array}{l}\text { Create gender 13sensitive school environment for girls by } \\
\text { supplying sanitary facilities }\end{array}$ & 14 & 11 \\
\hline $\begin{array}{l}\text { Government to make the cost of education affordable to low } \\
\text { income parents }\end{array}$ & 9 & \\
\hline Setting up boarding facility for girls & & \\
\hline
\end{tabular}

Source; Field data (2015)

A look at table 6 clearly shows that the strategy for mitigating community level risk factors to girls participation in public day secondary schools in Naivasha Sub-county that was put forth by a majority of teacher respondents $(22 \%)$ was the need to lower the cost of secondary education followed by the need to create girl-friendly schools which was endorsed by $15 \%$ of the teacher respondents. the least cited suggestions which attached $8 \%$ and $7 \%$ of the teacher respondents respectively were sponsorship of needy girls in schools by NGOs and enforcement of laws safeguarding the rights of girls to education.

\section{V.Summary of The Findings of the Study}

The study found that three community-level risk factors that had the most negative effect on girls' participation in public day secondary schools in the study area including: negative peer influence in the community, high incidences of teenage pregnancies and poverty in the community. Drawing from the computed $\mathrm{R}^{2}$ value $\left(\mathrm{R}^{2}=.406\right)$, the study revealed that the selected community factors were lowering the rate of girls participation in public day secondary schools by almost $41 \%$.

\section{Conclusions}

The study concluded that that community level factors such as: negative peer influence in the community, high incidence of teenage pregnancies and poverty in the community had a negative influence on girls' rate of participation in public day secondary schools in Naivasha Sub-county. This implies that prevalence of the three community level factors were critical deterrents to girls participation and progression in public day secondary schools in the study area.

\section{Recommendations}

The study recommended that school, family and community partnerships would be appropriate in minimizing the effect of community level factor on girls' participation in schools. Through these collaborations, girl students could be consistently exposed to the superior benefits which would accrue to them by completing their secondary education. Such engagements should also target the issue of teenage pregnancy by for instance sensitizing girls on the dangers of pre-marital sex. The issue of poverty in the community which could be limiting the capacity of communities in the sub-county to offer the necessary resources to day schools should also be addressed by the relevant stakeholders. These, to name but a few include the county government and community based organizations. For instance, these entities could work with community leaders with a view to identifying the relevant income generating activities that can be initiated in the Sub-county. Such an initiative will undoubtedly capacitate parents economically thereby enabling them to have higher amounts of disposable resources to their daughters.

\section{References}

[1] Anderson, B. ( 1988) Girls Access To Primary Education In Pakistan. Palastan Press palastan. 
[2] Bern, S.L. (1981). Gender Schema Theory: A Cognitive Account of Sex-Typing. Psychological Review, 88, 354-364.

[3] Bern, S.L. (1993).The Lenses of Gender. Transforming the Debate on Sexual Inequality.New Haven:Yale University Press.

[4] Brock, C. and N.K. Cammish (1991). Factors Affecting Female Participation in Education in Six Developing Countries. ODA Research Project 4532, Serial No. 9, January, London.

[5] Brown, F. B. (1980). A Study of The School Needs. Phidela Kappan, 61,537 - 540.

[6] Bruns, B., Mingat, A. (2003). Achieving Primary Education by 2015 for Every Child.

[7] Chiuri, L. W. \& Kiumi, J. K. (2005). Planning and Economics of Education, Nairobi. Pangolin Publishers.

[8] Davidson, J. \& Kanyuka, M. (1990). An Ethnographic Study of Factors Affecting the Education of Girls in Southern Malawi. Chancellor College, Zomba.

[9] Eagly, A.H. (1987). Sex differences in social behavior: A social-role interpretation. Hillsdale, NJ: Lawrence Erlbaum.

[10] Fatuma, N. C. \& Sifuna, D. N. (2006). Girls and Women's Education in Kenya. Gender Perspectives and Trends. Nairobi: UNESCO.

[11] FAWE, (2005). Review of National Education Policies and Plans for Potential for Scaling up Good Practices in Girl's Education. Nairobi: FAWE.

[12] FAWE, (2009). Closing the Gender Gap in Education: Curbing Dropout. Nairobi: FAWE.

[13] Girl Child Network, (2008). Factors Influencing Girls Participation in Free Primary Education. Nairobi, CEF.

[14] Kainja, K. \& Mkandawire, F. (1989/ National Case Study on the Role of Female Teachers in

[15] Kapakasa, A. M., (1992). Determination of Girls Participation and Persistence in Schools in Malawi.World Bank Population and Human Resource Division Southern Africa Department.

[16] Kendall, N. 2006. "Strengthening Gender and Education Programming in the 21st Century." EQUIP 2 Working Paper. Washington, DC: AED.

[17] Kiome, R. J. (2015). Home, School and Personal Factors Influencing Girls completion Rate in Primary Schools in Nyandarua South Sub-County. Kenya. Unpublished. Med Thesis: Laikipia University.

[18] Kiumi, J. K., Kibe, S. M. \& Ng'ang'a, S. W. (2013). Influence of Pupil Teacher Ratio and School Location on Pupils Performance in Kenya's Free Primary Education Program. International Journal of Economy Management and Social Science. 2(6), pp. 423-431.

[19] Lloyd, C. B. \& Mensch, B. S. (2008). "Marriage and Childbirth as Factors in Dropping Out from School: An Analysis of DHS Data from sub-Saharan Africa", Population Studies 62(1): 1-13.

[20] Ministry of Education (2005). Gender Policy on Education. Nairobi: Government Printer.

[21] Ministry of Education, (2008). Guidelines on Implementation of Free Secondary Education. Unpublished Education Circular. Nairobi: Ministry of Education.

[22] MOEST, (2005). A Policy Framework for Education Training and Research. Sessional paper No.1 of 2005. Nairobi: Government Printer.

[23] Mutambai, B. (2005, October). A Case Study on Teenage Pregnancy. School Times. Educational Insight Magazine. pg 42.

[24] Okumu, B. (1995). The Situation of the Female Child. A case study of Nairobi. (irlibrary.ku.ac.ke/bitstream/handle/123456789/6466).

[25] Omare, M. R (2007). Challenges Facing Girl Child in Accessing Secondary School Education in Suneka Division of Kisii District. Unpublished Project Report, UON. The standard 26th October 2009.

[26] Psacharopoulous, G. Z (1987). Returns to Education: An International Comparison. Amsterdam: Eseview.

[27] Republic of Kenya (2005). Sessional Paper No.1 on a Policy Framework for Education, Training and Research. Nairobi Government Printer.

[28] Republic of Kenya (2006). Ministry of Education Strategic Plan:2006 - 2011.Nairobi. Government Printer.

[29] Republic of Kenya, (2010). The Constitution of Kenya. Nairobi Government Printer.

[30] Republic of Kenya, (2013).The Basic Education Act,2013.Nairobi Government Printer. 
[31] Sifuna, D. N. (2006).Girls and Women's Education in Kenya. Gender Perspectives and the Enrolment and Persistence of Girls in Primary Schools. UNESCO. Malawi

[32] Todaro, M. P. (1985). Female migration: a conceptual framework. In Women in the Cities of Asia: Migration and Urban Adaptation, J. T. Fawcett, Siew-Ean Khoo and P. C. Smith, editors. Boulder, Colorado: Westview Press. Trends. Nairobi: Initiative Publishers.

[33] UNESCO, (2003). Gender education for all, the leap to equality. Paris: UNESCO.

[34] Wamahiu, S. P. Opondo, J. \& Nyagah, G. N. (1992). Educational Situation of the Kenya Girl Child. Nairobi: UNICEF \& ERNIKE.

[35] Wanjiru, N. (2007). Factors Contributing to School Dropout in Mombasa District Kenya. Unpublished M.Ed. Thesis. Nairobi: University of Nairobi.

[36] Wanyoike, W. (2003).Understanding Youth and Family from a Christian Perspective. Washington DC: World Bank.

[37] World Bank (1989). Sub-Saharan Africa: From Crisis to Sustainable Growth. Washington DC: World Bank.

[38] World Bank. ( 1996). Leveling the Playing Field: Giving girls an equal chance for basic education: Washington D.C:The World Bank.

[39] Yieke, F. (2015). Expanding Gender Spaces in Democratic Developmental African Project. Journal of Social Sciences, Education and Humanities, Vol.2, No.1, pp.78-104. 